\title{
Discussion about citizens' cooperation in a new waste separation rule through a social experiment on the collection of separated food waste in Toyohashi City, Japan
}

\author{
T. Okayama \\ Department of Human Life and Environment Studies, \\ Taisho University, Japan
}

\begin{abstract}
In recent years, especially since the Japan earthquake 2011, recycling and utilization of organic waste attracts attention in Japan. For example, the Ministry of Agriculture, Forestry and Fisheries (MAFF) announced "the biomass industrial town plan" to encourage local biomass industries and the reinforcement of the selfsustaining local energy supply system. In 2012, the Ministry of Economy, Trade and Industry (METI) carried out an Act on Special Measures concerning Procurement of Renewable Electric Energy by Operators of Electric Utilities and began the Feed In Tariff (FIT) that power companies have to buy the generated electricity by renewable energy for 20 years at a fixed price.

In response to such a national request, Toyohashi University of Technology, Nagoya University (later, changed to Taisho University) and Aichi Prefectural Government started an experiment to utilize biogas by methane fermentation of sewage sludge and food waste at the Toyogawa sewage disposal plant in Aichi Prefecture, in October 2011. In the experiment, biogas was used to generate electricity, and the carbon dioxide included in biogas was applied for photosynthesis to accelerate culture of vegetables and seaweed.

In this project, Tomoko Okayama (the author) of Taisho University was in charge of investigating the collection of food waste which became the raw materials for the biogas. From May to July 2014, I carried out a social experiment that approximately 400 households nearby the Toyogawa sewage plant separated food waste at the source, and the food waste was collected to the sewage plant to be anaerobic digested. I will mainly report on this social experiment and analyze
\end{abstract}


the amount of collected food waste, finally have a discussion on citizens' cooperation to separation of food waste from combustible waste at the social experiment, and provide information that will contribute to real policy making in the city of Toyohashi.

Keywords: food waste, municipal solid waste, separation of waste, social experiment, citizens' cooperation.

\section{Introduction}

\subsection{Policies on biomass resource usage in Japan}

In 2002, the Japanese cabinet approved the Biomass Nippon Strategy. Municipalities nationwide announced plans to utilize the biomass within their areas and sought the implementation of those plans. With widespread coordination among those involved in the regions, a comprehensive usage system was built, forming an efficient process from the creation of biomass to its use. The goal was to utilize biomass in a stable and appropriate way, and the plans created by municipalities and the like were referred to as "biomass town plans." By the time the biomass-town-concept announcements concluded in 2010, a total of 318 municipalities had announced plans for such towns. Additionally, the term "biomass" used here refers to organic waste (waste paper, livestock waste, food waste, wood from construction work, sawmill remnants, sewage sludge), unused biomass (rice straw, straw, chaff, timber from forest thinning), and resource crops (sugar cane, corn).

The Basic Act for Promoting the Use of Biomass was enacted in 2009, and the Basic Plan for Promoting the Use of Biomass was formulated in 2010. Furthermore, a biomass commercialization strategy was crafted at the Biomass Use Promotion Conference held by seven ministries, including the Ministry of Agriculture and the Ministry of Forestry and Fisheries (MAFF) in September 2012. Recruitment for the publicizing of the Biomass Industrial Community Plan began in 2013, and 16 municipalities have made announcements regarding the plan so far. Additionally, amendments for the Food Recycling Law were submitted in 2014, and it was decided that further advances would be made in the reduction of food waste. The use of biomass should be promoted because it is a carbon-neutral energy source and, within the category of biomass, the reuse and recycling of organic waste, which does not compete with food, deserves the most promotion.

In 2012, the Ministry of Economy, Trade and Industry (METI) carried out Act on Special Measures Concerning Procurement of Renewable Electric Energy by Operators of Electric Utilities and has begun the Feed In Tariff (FIT) that power companies had to buy the generated electricity by renewable energy for 20 years at a fixed price.

According to those laws, acts and plans, it is clearly understood that Japanese government regards food waste recycling especially heat recovery and generation by biogas as important policy. 


\subsection{Organic waste recycling policy: goals and issues}

By weight, food waste (kitchen waste) is the most common component of municipal waste. In particular, food waste makes up a larger proportion of municipal waste in Asia than it does in Europe and North America. Further, because food waste is over $80 \%$ water, it is not suitable for disposal by incineration. Accordingly, rather than disposing of food waste as combustible waste through incineration, it is separated out and goes through methane fermentation, producing biogas. This is an efficient method of waste disposal in Asian cities, for biogas businesses that deal with biogas-based electricity generation and heat utilization.

One issue for the biogas industry is the fact that it requires citizens to separate food waste and to cooperate with policies in order to operate. Furthermore, in order to obtain the largest amount of energy, policies that attempt to obtain the maximum amount of cooperation from citizens are necessary. Although it depends on policy goals, aiming to maximize the food waste collected is not always necessary for running a biogas business that disposes of waste. However, if "waste to energy" is the policy goal, the government must build a structure in which as much food waste as possible is steadily collected as an energy resource.

Specific policy examples and issues are introduced below. Starting in 2017, Toyohashi City in Aichi Prefecture Japan, which has a population of approximately 380 thousand people, will begin separately collecting food waste, which is municipal solid waste, from residences and businesses (supermarkets, restaurants, and so on). There will also be a PFI (Private Finance Initiative) business in which Toyohashi City's Nakajima Sewage Treatment Plant takes the 59 tons/day of food waste and 53 tons/day of sewage sludge collected, puts it through the methane fermentation process and generates biogas-based electricity, then carbonizes the digested sludge and sells it off. Accordingly, all citizens and businesses, such as supermarkets, will be required to separate out the food waste they generate, rather than include it with combustible waste as in the past.

For the citizens of Toyohashi, this means adopting new rules for municipal waste while for PFI businesses, it means generating electricity as part of their business in addition to waste treatment. Because the amount of biogas and electricity generated is proportional to the amount of food waste collected, PFI businesses are likely to request that the city collect as much food waste as possible. Meanwhile, Toyohashi City will commission the treatment of a daily maximum of 59 tons of food waste to PFI businesses, and it is also policy target of Toyohashi City.

\section{Social experiment: separation and collection of food waste}

\subsection{Estimates of food waste collection amount and separation cooperation rate in Toyohashi City}

For food waste generated by businesses, the available amount of food waste produced by businesses like supermarkets within Toyohashi City is estimated to be 4,700 ton/year (Aichi Prefecture Biomass Utilization Review Meeting Report, 
2011), while the daily amount is estimated to be 12.8 tons. Thus, if $85 \%$ of the available amount is collected, 10.6 ton/day (metric tons per day) can be collected.

Because the average amount of food waste per capita per day is $234 \mathrm{~g} / \mathrm{day}$ (The current state of the trash and match in the city, Toyohashi city, 2014) and the population of Toyohashi city is 378,890 (December, 2014), the available amount of food waste generated by households is estimated to be 88.7 ton/day. Thus, if $62 \%$ of the available amount is collected, 55 ton/day can be collected.

Overall, an $85 \%$ cooperation rate from businesses and about $60 \%$ cooperation rate from citizens is expected in Toyohashi City. However, population of Toyohashi City is now the most and at a time when the housewives is shrinking because of the falling birth rate and the aging population, the collection target is also maximum and it is regarded that the collection amount of food waste in Toyohashi City's PFI project will be decreasing.

\subsection{Overview of a social experiment for food waste collection planning}

Seeing trends like those above in the national policy and Toyohashi City policy, Toyohashi University of Technology and Taisho University (author) carried out a research project called the "Toyogawa Biomass Park Project" from 2011 to 2015. The project was conducted as follows (see Figure 1). At the Toyogawa Sewage Disposal Center where is in Toyohashi City, which treats sewage from the four cities of Toyohashi, Toyokawa, Gamagori, and Shinshiro in Aichi Prefecture, sewage sludge and food waste went through methane fermentation (co-digestion). Energy was generated from the obtained biogas and the $\mathrm{CO}_{2}$ produced was used for accelerated culture at vegetable greenhouse and seaweed greenhouse.

\section{TOYOGAWA BIOMASS PARK PROJECT}

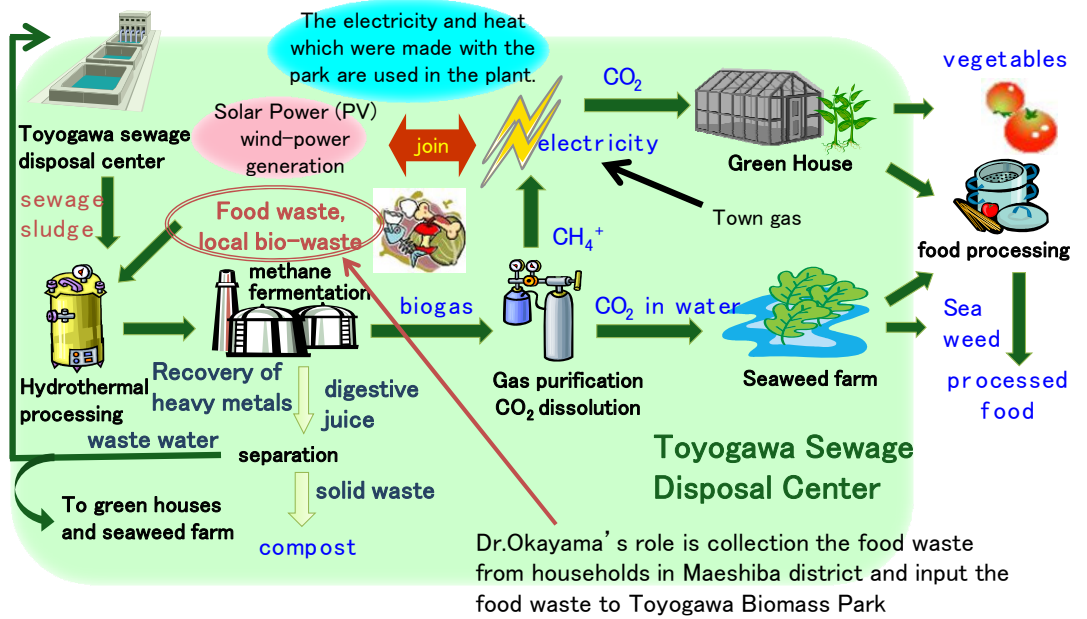

Figure 1: Research project overview and author responsibilities. 
The author's role in this project was to collect the food waste from households in Maechiba district that is Maeshiba elementary and secondly school ward, and input of the food waste to Toyogawa Biomass Park. So, the author was formulating and implementing the new separation rules, namely, to collect food waste separately and to recycle the food waste. This activity was a social experiment in which, unlike normal government plans, not only the government but also others like citizens and businesses, come together to formulate food waste separation plans; then implement those plans. One goal of this social experiment was to promote effective use and recovery of heat energy related to food waste that is currently being incinerated. The second goal was to create "social capital" related to the building of a Sound Material-cycle society, in other word 3R Society. (This is nearly the same as the concept of regional environmental governance capacity in Japan's annual environmental white paper, defined as the condition in which regional stakeholders are seen to be participating and cooperating in order to solve environmental issues.) To achieve these goals, the environmental burden of the waste treatment flow would be minimized using methods such as reducing the amount of intermediate disposal (such as incineration), and to establish evidence for the adoption of waste management systems that maximize environmental efficiency. The research was to involve the area project target: the Maeshiba Community, which is made up of five neighborhood (resident) associations in Toyohashi City.

In the two-month period from May to July 2014, collection according to the new waste separation-model for household-generated food waste was implemented in the Maeshiba Community, which is the community to be the nearest to the Toyogawa Sewage Disposal Center. The collected food waste was brought into the experimental facility of the Toyogawa Biomass Park for this project, and submitted to test sampling to investigate how much biogas and electricity could actually be obtained from this food waste.

Herein, the results of this social experiment are reported, and a discussion provided about the participation rate for food waste separation, in particular. In addition, suggestions are offered for the PFI work to be started in 2017 by Toyohashi City, regarding expected separated food waste collection amounts and other issues related to separate collection of food waste implemented by Toyohashi City.

\section{Methods of social experiment}

The social experiment proceeded as follows. The Maeshiba Community Committee for Implementing a Social Experiment on the Separated Collection of Biomass and Food Waste (referred to as the Citizens' Committee below) was formed on 22 March 2013, and has taken the approach of making all decisions at those talks. This is a so-called citizen-participation meeting or multi-stakeholder meeting, which supports the approach of building consensus through discussions between stakeholders. The members of the Citizens' Committee include chairpersons and vice chairpersons from each resident associations, relevant businesses in the area (general waste treatment businesses, recycling businesses, 
and others), citizens and citizen groups in the area, the relevant local governments (Toyohashi City and Aichi Prefecture), and researchers (the author and others). The Citizens' Committee has held meetings every month since its founding.

Several social surveys were carried out by the Citizens' Committee during planning and implementation of the collection of separated food waste. First, the "Survey on Municipal Waste Separation" was given to residents of the HigashiMikawa area (see Figures 2 and 3), east part of Aichi prefecture in Japan in March 2013 as a web questionnaire. Based on these results, it was proposed to the Citizens' Committee that food waste and other combustible waste be put out separately on combustible garbage collection days, and that Bio-dedicated bags be used for collection as the dedicated bags. Through discussion during several meetings of the Citizens' Committee, the following steps were planned. During the separated food-waste collection period (Tuesdays and Fridays from 13 May to 4 July: 16 collections) each household would receive $16(10 \mathrm{~L})$ dedicated biodegradable plastic bags. Only food waste would be put in the dedicated bags. These bags would be placed in dedicated boxes set up at specific collection stations. Other details were also discussed.

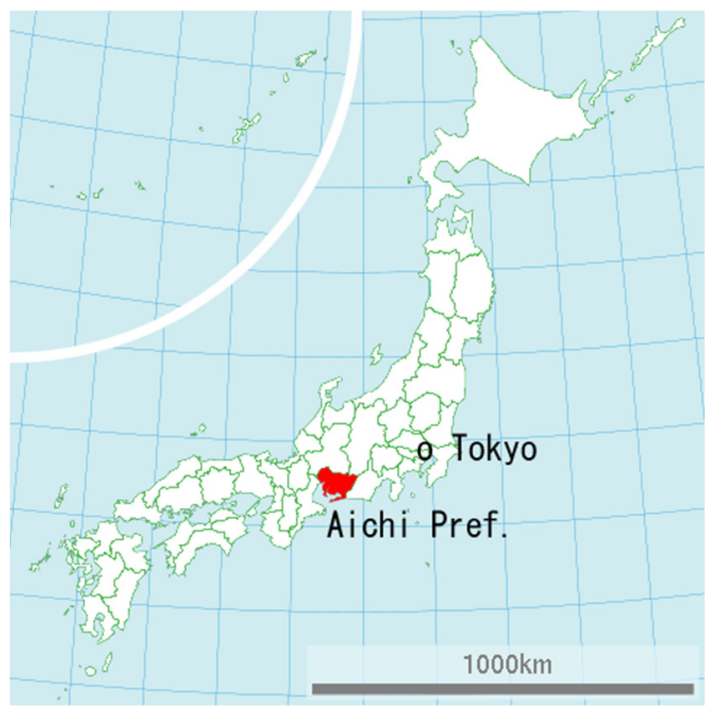

Figure 2: Location of Aichi Prefecture in Japan.

The Citizens' Committee spent the first year after its founding determining how food waste should be separately collected as described above, and then recruited participants in the area in question. Upon selecting the method for collection of separated food wastes, the research team attended neighborhood association meetings to explain the aims of the project and to ask for understanding. A questionnaire survey was done in the summer of 2013, to understand how each neighborhood felt about participating in this social experiment. Ultimately, the cooperation of 385 households was obtained. In March 2014, a survey of these 


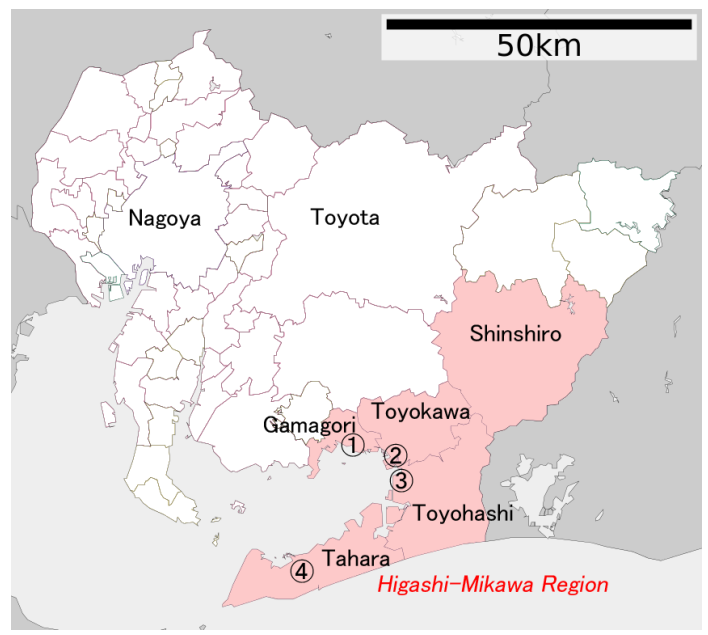

Figure 3: Sewage treatment plants locations in the Higashi-Mikawa region.

385 households was conducted prior to the social experiment. After this, the dedicated food-waste bags and a "Food Waste Separation Manual" summarizing separation and collection methods were created, and then distributed to the 385 households through the resident association presidents in April 2014, immediately before the social experiment began. Upon completion of the social experiment, a retrospective survey of the 385 households was conducted from July 2014. These results revealed citizen awareness and opinions about separation of food waste.

In addition, detailed combustible waste composition surveys of the area were conducted in the summer and winter of the year before the social experiment (2013), and detailed combustible waste and separated food waste composition surveys were conducted in 2014 while the social experiment was in progress. These results showed quantitatively the proportion of separated food waste and how the composition of general waste changed due to separation of food waste.

\section{Results of the social experiment}

Figure 4 shows changes in the amount of food-waste collected during the separated food-waste collection period. The average amount per collection was $296.6 \mathrm{~kg}$. As the researchers had planned to put $100 \mathrm{~kg}$ of food waste per day into the experimental verification unit, it can be said that each collection was more than adequate. There was approximately $1 \mathrm{~kg}$ of misplaced materials (such as plastic bags) mixed into the approximately $300 \mathrm{~kg}$ from the first collection, and a trend of increasing amounts of misplaced material was observed as more collections were done. Furthermore, for reasons that are unclear, the amounts collected declined steadily until the end of the experiment.

The collected food waste was subjected to hydrothermal treatment and, while gradually increasing the mixing ratio with sewage sludge (hydrothermally treated sludge + raw sludge), the input amount was planned such that on Day 30, the ratio 
Amount of collected food waste and No.of collection bags

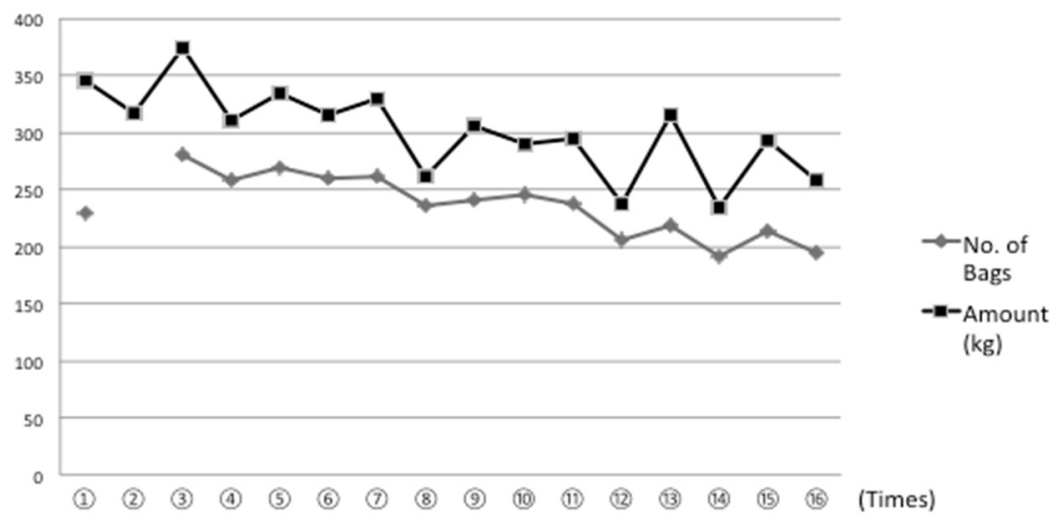

Figure 4: Changes in the amount of food waste collected during the social experiment.

of raw sludge to hydrothermally treated sludge to food waste, would be 1:1:1 inside the methane fermentation tub. As a result, $1 \mathrm{~kg}$ of Food waste of Maeshiba community included $7 \mathrm{~g}$ of carbon. Degradation rate is set to $80 \%$ as the premise. The methane concentration in the biogas is set to $60 \%, 40 \%$ is $\mathrm{CO}_{2}$. Then methane gas of $4.48 \mathrm{~kg}$ (about $7 \mathrm{~N} \mathrm{~m}^{3}, 70 \mathrm{~L}$ ) can be taken from food waste of $100 \mathrm{~kg}$. This is equivalent to $0.07 \mathrm{~m}^{3}$ of city gas. Moreover, sewage sludge produced about half the biogas that food waste did. If $300 \mathrm{~kg}$ of food waste per collection were sustained, then $21 \mathrm{~m}^{3}$ of city gas (methane) could be produced per collection, meaning that $336 \mathrm{~m}^{3}$ of methane would have been produced from the 16 times food waste collections during the social experiment.

The questionnaire survey after the social experiment showed that satisfaction was extremely high with the methods of collecting food waste on the same day as combustible waste, collecting with dedicated plastic bags, and collecting by putting the bags in dedicated boxes. There was a small difference between the survey responses (before and after) regarding the impact of adding a fee as an incentive for separation. In the survey beforehand, $43 \%$ indicated that a difference in cost was an incentive to separate, while $41 \%$ so indicated in the survey after the experiment. Adding a fee is considered effective for improving separation rates. In addition, the percentage of people who answered that they would separate food waste if it were less expensive was $26 \%$ in the survey after the social experiment, an increase of $10 \%$. However, the percentage of people who answered that they would always separate regardless of fees was unchanged at $43 \%$, and this group was the largest.

The detailed waste composition survey conducted during the social experiment in 2014 showed that kitchen waste made up 45\% of waste from households that do not separate food waste, while this figure was approximately $25 \%$ for households that do separate. For waste composition in which $100 \%$ of the material separated out is food waste, plant-based kitchen waste is the most common 
component at $80 \%$ liquid, followed by sweet at $6 \%$, after which come rice, and bread at approximately $3 \%$ and beverages at approximately $2 \%$. The rates of untouched food differ between households that participated in separation and households that did not separate. The percentage of food that was left without eating was $8.5 \%$ for non-separating households and $2.3 \%$ for separating households. Additionally, in interview surveys during the sampling period, it was revealed that no one-person households were participating in food waste separation.

\section{Discussion}

\subsection{Discussion on cooperation rates with separation during the social experiment}

(1) Neighborhood participation rate in the school district (percentage of households) $32 \%$

Among the five resident associations in the Maeshiba Community, Nishihamacho withdrew from the experiment. Ultimately, the total number of participating households (from among the participating Maeshiba Community neighborhoods of Umeyabu, Maeshiba, Hishikino, and Maeshiba household) was $32.4 \%$ of the entire school district. The reason for the withdrawal of Nishihamacho was that the resident association president believed participating would be difficult. There are a large number of apartments and young households in Nishihamacho, and the rate of participation in the resident association is low. Meanwhile, the other four neighborhoods are older and the rates of participation in their resident associations are high. However, in the city as a whole, situations like that in Nishihamacho are actually common.

(2) Participation rates according to an intention survey $48 \%$.

From July to August 2013, a survey on intent to participate in the separated food waste social experiment was provided to 810 out of 840 households. From these, 598 intention forms were received (a return rate of 74\%), and of these, intent-to-participate was received from 385 households. The participation rate for all households in the four neighborhoods (distribution number) was $47.5 \%$, while the intent-to-participate rate out of the number of intention forms was $64 \%$.

(3) Participation rate based on the number of bags collected during the social experiment $61 \%$.

During the social experiment, an average of 236.5 bags was picked up per collection, $61.4 \%$ of the 385 bags distributed.

(4) Participation rate based on the amount of food waste collected during the social experiment $55 \%$.

If $1400 \mathrm{~g}$ of food waste were collected from 385 households per collection (assuming waste production of an average of $400 \mathrm{~g} / \mathrm{d}$ per household, with one collection picking up 3.5 days' worth of waste), approximately $540 \mathrm{~kg}$ could be expected per collection. However, the actual collection amount was $296.6 \mathrm{~kg}$ per collection, $54.9 \%$ of the expected value. 
(5) Participation rate based on an interview survey 55\%.

According to an oral survey conducted at Maeshibacho Station on 27 June 2014, out of 36 households who responded that they were participating in the separated food waste social experiment, 20 households (55\%) were actually separating out the food waste they generated.

(6) Participation rate based on the questionnaire return rate $54-58 \%$.

The number of valid responses to the survey questionnaire returned before the experiment (conducted in March 2014) was 225, a return rate of 58\%. The number of valid responses received from the retrospective questionnaire (conducted July to August 2014) was 208, a return rate of $54.0 \%$.

(7) Actual rate of separated food waste implementation (four neighborhoods) $28 \%$.

As (4), (5), and (6) generally agree, the actual amount of cooperation with the social experiment is considered to be $\sim 55 \%$ of households that agreed to participate. Although this figure was calculated as $61 \%$ in (3), if 225 households (58\%, median 59.5\%) actually participated, this means that, ultimately, the percentage that actually separated food waste in the four neighborhoods was $27.5 \%$. Therefore, taking into account (1) through (6) collectively, it should be safe to anticipate a cooperation rate for food waste separation of about $30-50 \%$ in Toyohashi City.

Furthermore, according to a report out of Kyoto [1], a model experiment on separated collection of food waste conducted in Kyoto from October to December 2008, and from April to September 2009, resulted in a median participation rate of $35.5 \%$. This was based upon an estimate of model-experiment-participation households for the entire model area (estimated using the number of bags of food waste generated $\div$ average number of bags generated). The ultimate participation rate was around $30 \%$ for Kyoto as well.

\subsection{Opinions offered by Toyohashi City regarding collection of separated food waste}

Toyohashi City plans to process approximately 50 ton of household-generated food waste daily (about 59 ton/day when business-generated food waste is added) during collection of separated food waste from 2017 on.

The amount of waste in Toyohashi City is more than the national average, the discharge of waste per person per day is estimated as with $234 \mathrm{~g}$ /day more than national average, too (Toyohashi city, 2014). So if the food waste produced per household per day were, accordingly, $612 \mathrm{~g}$ (average number of family was 2.615 in 2014), 44 ton/day could be reached with a 50\% cooperation rate. However, if the cooperation rate were $30 \%$, an approximate daily amount of 29 tons could be expected. If about $50 \%$ of business-generated food waste were collected, that means that 6 ton/day could be collected. When this work begins, it would be favorable to start by collecting about 30 tons of household-generated food waste and gradually increase this amount. In other words, the researchers propose a business plan in which operations start by co-digesting about 36 tons of food waste 
relative to the 53 ton per day of sewage sludge, gradually increasing the amount of food waste.

Because this social experiment made thorough use of regional organizations such as school ward and resident associations to design and implement a separated collection plan, rates of citizen recognition and cooperation rates in the target area were high. Even so, cooperation rates settled around $60 \%$. In other words, citizen participation and cooperation between business, academia, and citizens alone are not enough to raise separation cooperation rates for actual PFI businesses in Toyohashi City. It is important to combine them concurrently with other political techniques, such as financial incentives to encourage waste producers to separate.

\section{References}

[1] Kyoto Environmental Policy Bureau: 2009 Report on Model Experiment Research on the Creation of New Energy through Separated Collection of Food Waste Etc. March 2010.

[2] Tomoko Okayama, Discussion on Citizens' Cooperation Rate to Separate Food Waste from Combustible Waste at a Social Experiment in the City of Toyohashi, "International Symposium on EcoTopia Science 2015 (ISETS '15) -Innovation for Smart Sustainable Society-", November 27 to 29, 2015, Nagoya University, on CD-ROM

[3] Tomoko Okayama: potential for introducing organic waste diversion to municipal solid waste management in Asia, the 3rd International Scientific Conference on Material Cycles and Waste Management (3RINCs) pp. 127130. 